\title{
A INFLUÊNCIA DO ETANOL COMBUSTÍVEL NA EMISSÃO DE ETANOL, ALDEÍDOS E HIDROCARBONETOS EXPELIDOS PELO ESCAPAMENTO EM VEÍCULOS LEVES
}

\author{
Raphael Bellis de Sousa ${ }^{1}$, Vanderlei Rodrigues Ferreira ${ }^{1}$, Rui de Abrantes ${ }^{1}$ e Vanderlei \\ Borsari $^{1}$ \\ ${ }^{1}$ CETESB - Companhia Ambiental do Estado de São Paulo \\ E-mails: bellischemistry@gmail.com,vrferreira@sp.gov.br,ruiabnt@gmail.com e \\ vborsari@sp.gov.br
}

\begin{abstract}
RESUMO
Os primeiros estudos brasileiros de veículos utilizando como combustível o etanol ou álcool etílico, incluindo suas misturas com gasolina, datam da década de 1920, sendo representados pelo automóvel mais antigo que se tem notícia a rodar com etanol no Brasil. A partir deste marco, inúmeras foram as evoluções tecnológicas ligadas à indústria automobilística e a indústria do etanol, motivadas principalmente pelas crises do mercado de petróleo e por políticas de incentivo à indústria canavieira, e, mais recente, pela motivação ligada à forte necessidade de atendimento aos anseios dos consumidores em relação ao consumo de combustível e políticas mais rigorosas de controle de emissão de poluentes. Este trabalho tem o objetivo de realizar um breve levantamento histórico das informações citadas, por meio de fontes de referências e alguns testemunhos. Também se avalia como a utilização de etanol afeta a emissão de hidrocarbonetos pelo escapamento dos veículos rodoviários automotores leves, incluindo a emissão de aldeídos e do próprio etanol. [1,2]
\end{abstract}

\section{INTRODUÇÃOO}

\section{HISTÓRICO DOS VEÍCULOSA ÁLCOOL}

\subsection{Veículos dedicados a álcool}

Devido às particularidades de nosso país, como extensas áreas para agricultura, além de solo e clima adequados, desde cedo houve inúmeros estudos para a utilização de álcool em motores automotivos. Já na década de 1920, o INT, então chamado de Estação Experimental de Combustíveis e Minérios (EECM) testou um FORD de quatro cilindros, o carro mais antigo que se tem notícia a rodar com álcool no Brasil. Em agosto de 1925, o Ford percorreu $230 \mathrm{~km}$ em uma corrida no Circuito da Gávea, no Rio de Janeiro, na primeira prova automobilística realizada pelo Automóvel Clube do Brasil. [1,2] 


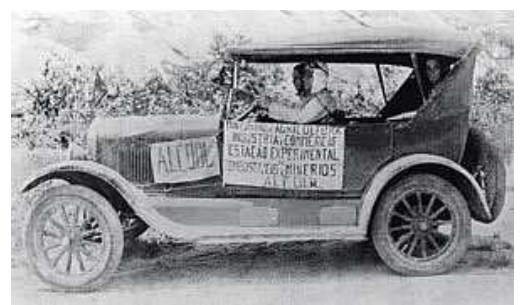

Figura 1. Carro mais antigo que se tem notícia a rodar com álcool no país, dirigido pelo piloto e coordenador do projeto engenheiro Heraldo de Souza Mattos. [2]

Com um consumo ótimo para a época, $5 \mathrm{~km} / \mathrm{L}$, o combustível era o álcool etílico hidratado $70 \%$ (com $30 \%$ de água). "Era quase aguardente", disse o químico Abraão Iachan, assessor da diretoria do Instituto Nacional de Tecnologia (INT). A cachaça tem entre $38 \%$ e $54 \%$ de álcool em sua composição. [2]

O engenheiro civil Ernesto Lopes da Fonseca Costa, que dirigia a EECM, já afirmava, em seu trabalho publicado em 1927, que a produção mundial de petróleo começava a se tornar insuficiente para o consumo, que não se mantinha estacionário. Em 1920, o consumo de petróleo no mundo já era de cerca de duas mil vezes o de 1860.[2]

Outros representantes de nossa sociedade já comentavam o assunto. O presidente Epitácio Pessoa (1919-1922) já reclamava em 1922 da "colossal importação de gasolina no Brasil", aludia ao "uso do álcool em seu lugar" e previa o "amparo que a solução prestaria à indústria canavieira". O governo seguinte, de Arthur Bernardes (1922-1926), encomendou à EECM um projeto de desenvolvimento de motores a álcool, que pudesse também servir de base para legislação sobre o assunto.[1,2]

A prioridade da EECM era como tornar viável a mistura do álcool com a gasolina importada e não substituir inteiramente um combustível pelo outro. Essa mistura passou a ocorrer obrigatoriamente na década de 1930, com várias leis municipais, estaduais e federais que estabeleciam a adição de $5 \%$ a $10 \%$ de álcool à gasolina.[1,2]

$\mathrm{Na}$ França havia pesquisas sobre o poder carburante do álcool em motores a explosão. E outros países, como Inglaterra, Alemanha, Holanda e África do Sul, tiveram experiências semelhantes, todos antes do Brasil.[2]

Foi na segunda metade dos anos 1970 que o investimento científico e governamental no Programa Nacional do Álcool, o Proálcool, levou o país a tornar-se a principal referência mundial nesse combustível por meio de experiências duradouras e economicamente bem-sucedidas.[2]

O Pró-álcool foi impulsionado devido a escassez da gasolina que também se tornava mais cara, decorrente de duas crises do petróleo. As principais características que fizeram o Pró-álcool obter sucesso durante certo tempo foi o baixo preço do açúcar, a instalação de novas usinas e modernização da infraestrutura já em funcionamento, domínio da fabricação do álcool, diminuição da poluição e criação de milhares de postos de trabalho. [3] 
Porém, em 1985 o petróleo passou por um momento de queda abrupta no mercado internacional, foi quando os produtores nacionais de etanol produziram menos, de olho nas vantagens de se investir em açúcar. Os erros cometidos pelos usineiros e pela política governamental trouxeram incertezas ao consumidor, que notou a falta de álcool nos postos.[3]

Os gráficos de produção e licenciamento de veículos leves de passageiros novos por combustível entre o período de 1979 e 2011, Figuras 01 e 02, mostram que a produção de veículos dedicados a etanol compreendeu entre os anos de 1979 e 2006 tendo seu ápice na década de 1980. O período descrito pode ser subdividido em mais dois subperíodos, compreendidos entre 1979 e 1989, e, 1990 e 1995, estando associado às crises do mercado de petróleo, encarecendo o preço de combustíveis fósseis. $[3,4]$

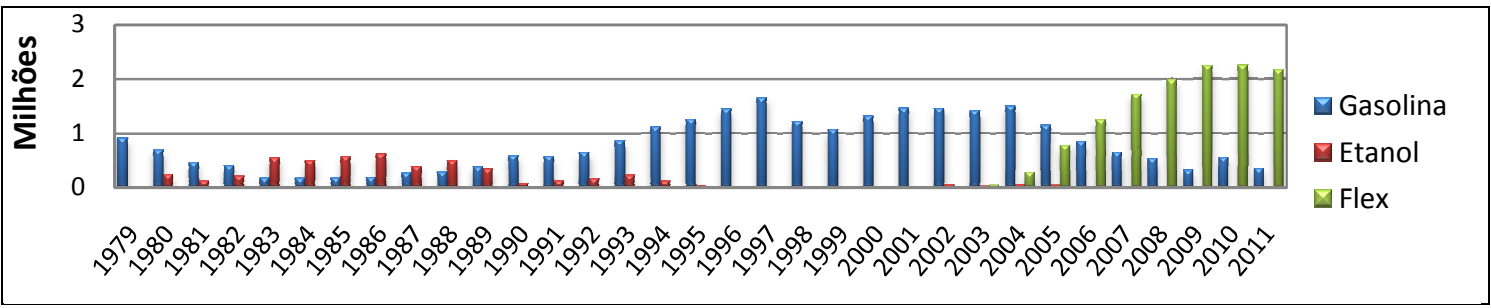

Figura 01. Produção de veículos leves de passageiros por combustível entre o período de 1979 e 2011. [4]

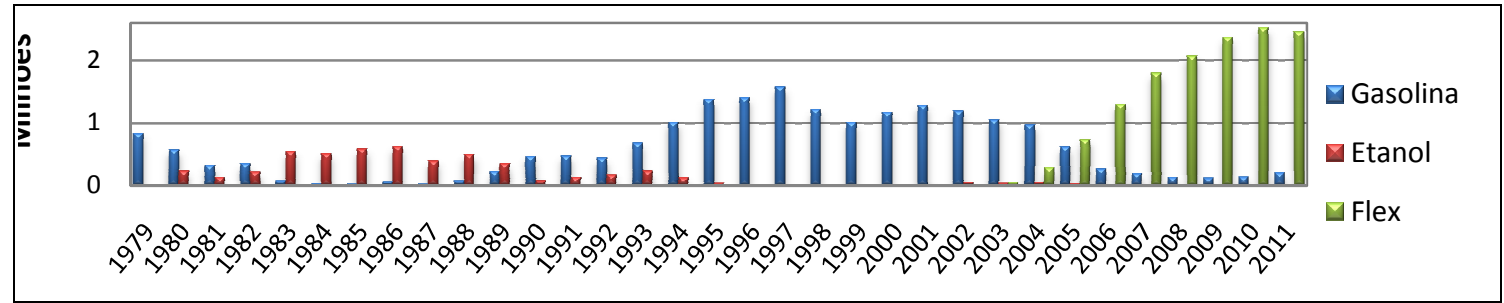

Figura 02. Licenciamento de veículos leves de passageiros novos por combustível entre o período de 1979 e 2011 . [4]

Os gráficos das Figuras 01 e 02 também mostram que são muito semelhantes entre si, ou seja, a grande maioria dos veículos leves de passageiros produzidos no Brasil alimentava o próprio mercado interno.

\subsection{Veículos flex}

Na década de 1990 a maioria das montadoras não oferecia mais modelos novos movidos a etanol. Porém, em 2000ao mesmo tempo em queuma nova alta no preço do petróleo ocorria, o preço do etanol, afetado porpouca demanda, estava em baixa. Tal situação provocou um fenômeno curioso: os motoristas passaram a misturar, por conta própria, álcool à gasolina na hora de encher o tanque, mistura conhecida como "rabo-de-galo", quando se começou a discutir a possibilidade de projetar carros flex nas montadoras de automóveis. $\left[3,{ }^{5,},\right]$

O sinal de que o veículo flex seria de fato viável foi dado no fim de 2002, quando a isenção de IPI para essa categoria de carros, que nem sequer existia oficialmente, foi aprovada. Disponíveis no mercado desde 2003, os veículos flex resultaram um sucesso comercial e já em Agosto de 2008, a frota de automóveis e veículos 
comercias leves tipo "flex" tinha atingido a marca de 6,2 milhões de veículos, representando um $23 \%$ da frota de veículos leves do Brasil. [5,6]

O sucesso dos veículos "flex", conjuntamente com a obrigatoriedade ao nível nacional de usar de 20 a 25\% de etanol com gasolina (E25), permitiu ao etanol combustível superar o consumo de gasolina em abril de 2008. A tradição e cultura no uso do etanol como combustível, herança do programa Pró-álcool, favoreceu a rápida aceitação dos veículos flex no Brasil e seu sucesso comercial. Quando os autos flex foram oferecidos no mercado brasileiro, o país já tinha 30.000 postos de gasolina prontos para vender etanol em todo o país.[5,6]

\subsection{Histórico da implantação de veículos flex do ponto de vista do PROCONVE}

A introdução dos veículos flex no mercado brasileiro em 2003 levou a necessidade de rediscussão da metodologia de cálculo de NMHC, para viabilizar a sua implantação, principalmente quando se realiza ensaios com etanol hidratado combustível, EHC. [7]

A primeira consequência desta discussão foi a introdução do desconto de etanol dos hidrocarbonetos não metano, acompanhado da introdução do conceito de fator de resposta de etanol do detector de ionização de chama, DIC, em ensaios que utilizam etanol hidratado combustível. O fator de resposta de etanol do DIC pode ser definido, de maneira simples, como um fator necessário para correção dos valores de etanol medidos em um detector calibrado com etanol para serem utilizados com dados de hidrocarbonetos adquiridos em outro detector calibrado com propano. [7]

A segunda consequência foi definir como o desconto de etanol dos hidrocarbonetos não metano seria empregado, em termos de massa ou de concentração. Após várias discussões, o desconto por concentração foi escolhido. [7,8]

E a terceira consequência foi a introdução do conceito de fator de resposta de metano do DIC, que também pode ser definido como um fator necessário para correção dos valores de metano medidos em um detector calibrado com metano para serem utilizados com dados de hidrocarbonetos adquiridos em outro detector calibrado com propano, em ensaios que utilizam gasolina, etanol, suas misturas e diesel.[7,8]

Como o PROCONVE não estabelece limites máximos de emissão de etanol em gases de escapamento de veículos automotores, não houve preocupação inicial das emissões desta substância. Porém, como as emissões de etanol passaram a ser significativas em comparação aos demais componentes em ensaios com EHC, foi criado em março de 2012 o Grupo de Trabalho Especial de Álcool Não Queimado, GTE de ANQ, para aprofundar as discussões sobre o assunto. $\left[9,{ }^{10}\right]$

\section{DEFINIÇÕES E CONSIDERAÇÕES}

\subsection{Definições e proposta}

A principal consequência das grandes emissões de etanol nos gases de escapamento de veículos automotores abastecidos com EHC se dá de modo indireto, pois o etanol é um dos precursores do ozônio troposférico, considerado um poluente. [11] 
Para avaliar qual é a contribuição das emissões de etanol citadas, devem-se definir os seguintes termos:

MIR (Maximum Incremental Reactivity):Máximo incremento em massa de ozônio formado pela adição de um composto a "Mistura Base ROC" por massa de composto adicionado, expressa em [ $\left.\mathrm{g} \mathrm{O}_{3} / \mathrm{g} \mathrm{ROC}\right]$ - Escala de reatividade de um dado composto na formação de ozônio troposférico $\rightarrow$ Massa de ozônio formado por massa de composto em condições controladas (simulação da troposfera). [11]

Bin: Sistema constituído de 24 tipos diferente de misturas de hidrocarbonetos, tanto em natureza como em composição de seus constituintes (Tradução literal "caixa"). [11]

ROC (Reactive Organic Compound): Qualquer composto que tenha potencial, uma vez emitido, de contribuir com a formação de ozônio troposférico.[11]

VOC (Volatile Organic Compound): Qualquer composto contendo pelo menos um átomo de carbono, excluindo o monóxido de carbono, dióxido de carbono, ácidos carbônicos, carbetos ou carbonatos metálicos e carbonato de amônio, metano, dentre outros. Acetona e etano são exemplos de compostos de baixa reatividade.[11]

NMOG (Non-methane organic gas): Refere-se aos gases orgânicos não metanos, dados pela soma de poluentes, como os hidrocarbonetos não metano não oxigenados, NMHC, compostos carbonílicos (aldeídos e cetonas), CHO, e alcoóis, $\mathrm{COH}$, sendo representada de modo genérico pela Equação 01. [12]

$\mathrm{NMOG}=\mathrm{NONMHC}+\mathrm{COH}+\mathrm{CHO}$ (Equação 01)

NONMHC (Non-Oxygenated Non-MethaneHydrocarbon): Refere-se aos hidrocarbonetos não metano não oxigenados, ou seja, os hidrocarbonetos com desconto de metano, álcoois e compostos carbonílicos (Equação 02). [11]

$\mathrm{NONMHC}=\mathrm{HC}-\mathrm{CH}_{4}-\mathrm{CHO}-\mathrm{COH}$

(Equação 02)

A base da proposta apresentada neste trabalho está emdescrever um procedimento para cálculo e controledas emissões ponderadas dos compostos NMOG, sendo os principais poluentes das emissões veiculares que contribuem para a formação de ozônio troposférico com considerável impacto à saúde pública.[11]

Como já existem limites máximos de emissão de hidrocarbonetos não metano e de aldeídos totais, bastaria criar um limite máximo de emissão de NMOG, e, assim, controlar indiretamente as emissões de etanol.

O conceito MIR e seus valores seriam empregados apenas para auxiliar na escolha de um possível limite máximo de emissão de NMOG.

Também é necessário levar à discussão a necessidade de atualização ou não da metodologia de cálculo e limites máximos de emissão de poluentes referentes aos hidrocarbonetos não metano, NMHC, em relação aos hidrocarbonetos não metano 
não oxigenados, para ensaios de veículos rodoviários automotores leves abastecidos com gasolina, etanol, suas misturas e diesel.

\subsection{Valores de MIR}

A literatura disponibiliza valores de MIR de uma variável classe de compostos, tanto para substâncias puras, como para misturas, porém para o nosso objetivo podemos reduzi-los aos relatados pelas Tabelas 01 a 03. [11]

Tabela 01.Valores de MIR para os compostos NMOG segundo o modelo de mecanismo SAPRC-07 do CARB, dados em [g O 3 /g ROC].

\begin{tabular}{cccccc}
\hline $\mathrm{MIR}_{\mathrm{ROC}}\left[\frac{\mathrm{g} \mathrm{O}_{3}}{\mathrm{~g} \mathrm{ROC}}\right]$ & 0,028 & 0,056 & 1,53 & 6,54 & 9,46 \\
\hline
\end{tabular}

Porém a obtenção dos valores de MIR dos hidrocarbonetos não metano, NMHC, e, dos hidrocarbonetos não metano não oxigenados, NONMHC, é mais complexa, por se tratar de uma mistura de compostos.

Devido ao exposto, pode-se atacar o problema de duas formas: (a) estimando-se os valores de NMHC e de NONMHC por meio de seus componentes teóricos; (b) medindo-se os valores de MIR para vários casos e tentar encontrar um valor médio.

Adotando-se a primeira estratégia, assumi-se, por aproximação, que o valor de MIR da gasolina é igual ao valor de MIR do NMHC e NONMHC.

Ambas as estratégias podem parecer que geram, em um primeiro momento, uma grande dispersão de valores de MIR, pois estes dependem da composição de uma dada mistura. Quando considera-se apenas a gasolina brasileira, há grande variação da composição desta dependendo do local e método de extração e refino (estratégia (a)), do mesmo modo que há grande variação na composição de NMHC e NONMHC emitidos pelos veículos dependendo de cada unidade (estratégia (b)).Porém, mesmo com essas variações, pode-se assumir um valor único, semelhante ao que é feito para a densidade dos hidrocarbonetos relatada na norma ABNT NBR 6601 (assumi-se uma relação carbono-hidrogênio média).

Então, segrega-se a gasolina em três classes de compostos: aromáticos, olefínicos e alcanos. As frações de cada classe são obtidas por meio das resoluções ANP que definem os limites máximos de compostos aromáticos e olefínicos contidos na gasolina comercial tipo $\mathrm{C}$ e de referência nacional. Assume-se que a diferença destas duas classes de compostos é constituída apenas de alcanos (Tabela 02). [13] 
Tabela 02. Frações da gasolina de referência e comercial, segundo limites máximos de hidrocarbonetos contidos em resoluções ANP e CARB e seus valores de MIR estimados. [13]

\begin{tabular}{lcccc}
\hline Hidrocarbonetos & $\begin{array}{c}\text { Gasolina de } \\
\text { referência - } \\
\text { L6 (Vigente) }\end{array}$ & $\begin{array}{c}\text { Gasolina } \\
\text { comercial - Tipo } \\
\text { C (Vigente) }\end{array}$ & $\begin{array}{c}\text { Gasolina comercial - } \\
\text { L6 - Tipo C } \\
(\mathbf{0 1} / \mathbf{0 1} / \mathbf{2 0 1 4})\end{array}$ & $\begin{array}{c}\text { Gasolina comercial } \\
\text { - Fase 3 - CARB } \\
\text { (Vigente) }\end{array}$ \\
Aromáticos & $35 \%$ & $45 \%$ & $35 \%$ & $25 \%$ \\
Olefínicos & $15 \%$ & $30 \%$ & $25 \%$ & $6 \%$ \\
Alcanos & $50 \%$ & $25 \%$ & $40 \%$ & $69 \%$ \\
\hline MIR $_{\text {gasolina }}\left[\frac{\mathbf{g ~ 0}_{\mathbf{3}}}{\mathbf{g ~ R O C}}\right]$ & $\mathbf{4 , 2 6}$ & $\mathbf{5 , 5 4}$ & $\mathbf{4 , 7 0}$ & $\mathbf{3 , 2 5}$ \\
\hline
\end{tabular}

Os valores de MIR de cada classe citada acima sãofornecidos pela Tabela 03 .

Tabela 03.Valores de MIR para algumas classes de hidrocarbonetos. [11]

\begin{tabular}{cc}
\hline Hidrocarbonetos & Valor de MIR - CARB 02/10/2010 $\left[\frac{\mathbf{g ~ O}_{\mathbf{3}}}{\mathbf{g ~ R O C}}\right]$ \\
Aromáticos & 7,65 \\
Olefínicos & 5,80 \\
Alcanos & 1,44 \\
\hline
\end{tabular}

Considera-se que a composição dos aromáticos da gasolina é igual ao Bin 21 (mistura definida com mais de $98 \%$ de aromáticos), de olefínicos é igual ao valor 5,80, e de alcanos é igual ao Bin 09 (mistura definida predominantemente de alcanos). [11]

\section{METODOLOGIAS DE CÁLCULO}

3.1. Cálculo de massa e massa ponderada de alguns componentes do gás de escapamento de veículos rodoviários automotores leves

A norma ABNT NBR 6601:2012, vigente desde 18 de outubro de 2012, descreve a metodologia de cálculo de massa relacionada às emissões de escapamento de metano, $\mathrm{CH}_{4 \mathrm{M}}$, e, hidrocarbonetos não metano, $\mathrm{NMHC}_{\mathrm{M}}$,em veículos rodoviários automotores leves abastecidos com gasolina, etanol, suas misturas, gás natural veicular e diesel (Equações 03 e 04). [8]

$$
\begin{array}{ll}
\mathrm{CH}_{4 \mathrm{M}}=\mathrm{v}_{\mathrm{ed}} \cdot \mathrm{d}_{\mathrm{CH}_{4}}\left[\mathrm{CH}_{4 \mathrm{e}}-\mathrm{CH}_{4 \mathrm{~d}}\left(1-\frac{1}{\mathrm{Rd}}\right)\right] 10^{-6} & \text { (Equação 03) } \\
\mathrm{NMHC}_{\mathrm{M}}=\mathrm{v}_{\mathrm{ed}} \cdot \mathrm{d}_{\mathrm{HC}}\left\{\mathrm{HC}_{\mathrm{e}}-\mathrm{HC}_{\mathrm{d}}\left(1-\frac{1}{\mathrm{Rd}}\right)-\mathrm{Fr}_{\mathrm{CH}_{4}}\left[\mathrm{CH}_{4 \mathrm{e}}-\mathrm{CH}_{4 \mathrm{~d}}\left(1-\frac{1}{\mathrm{Rd}}\right)\right]\right\} 10^{-6} & \text { (Equação 04) }
\end{array}
$$

Esta mesma norma também descreve a metodologia de cálculo de massa relacionada à emissãode escapamento de hidrocarbonetos não metano com desconto de etanol, $(\mathrm{NMHC}-\mathrm{ETOH})_{\mathrm{M}}$, para veículos rodoviários automotores leves abastecidos com etanol hidratado combustível (Equação 05). [14]

$$
\left(\begin{array}{c}
\mathrm{NMHC} \\
-\mathrm{ETOH}
\end{array}\right)_{\mathrm{M}}=\mathrm{v}_{\mathrm{ed}} \cdot \mathrm{d}_{\mathrm{HC}}\left[\left(\begin{array}{c}
\mathrm{NMHC} \\
-\mathrm{ETOH}
\end{array}\right)_{\mathrm{e}}-\left(\begin{array}{c}
\mathrm{NMHC} \\
-\mathrm{ETOH}
\end{array}\right)_{\mathrm{d}}\left(1-\frac{1}{\mathrm{RD}}\right)\right] 10^{-6} \quad \text { (Equação 05) }
$$


Enquanto a norma ABNT NBR 15598:2008, vigente desde 18 de setembro de 2008, descreve a metodologia de cálculo de massa relacionada à emissão de escapamento de álcoois, $\mathrm{COH}_{\mathrm{M}}$,em veículos rodoviários automotores leves(Equação 06). Dentre estes, o etanol é atualmente o álcool de interesse brasileiro, pois é utilizado como combustível nas misturas com gasolina ou como etanol hidratado combustível (Equação 07). [15]

$$
\begin{aligned}
& \mathrm{COH}_{\mathrm{M}}=\mathrm{v}_{\text {ed }} \cdot \mathrm{d}_{\mathrm{COH}}\left[\mathrm{COH}_{\mathrm{e}}-\mathrm{COH}_{\mathrm{d}}\left(1-\frac{1}{\mathrm{Rd}}\right)\right] 10^{-6} \\
& \mathrm{ETOH}_{\mathrm{M}}=\mathrm{v}_{\text {ed }} \cdot \mathrm{d}_{\text {ETOH }}\left[\mathrm{ETOH}_{\mathrm{e}}-\mathrm{ETOH}_{\mathrm{d}}\left(1-\frac{1}{\mathrm{Rd}}\right)\right] 10^{-6}
\end{aligned}
$$

E a norma ABNT NBR 12026:2009, vigente desde 01 de maio de 2009, descreve a metodologia de cálculo de massa relacionada à emissão de escapamento de compostos carbonílicos, $\mathrm{CHO}_{\mathrm{M}}$, em veículos rodoviários automotores leves (Equação 06). Dentre estes, o acetaldeído e formaldeído estão entre os principais compostos carbonílicos gerados na combustão dos combustíveis utilizados em nosso país (Equações 08 e 09). [14]

Outros compostos carbonílicos também podem ser emitidos durante a queima dos combustiveis utilizados no Brasil, principalmente quando se considera o diesel.

$$
\begin{aligned}
& \text { Acetaldeído }_{\mathrm{M}}=\mathrm{v}_{\text {ed }} \cdot \mathrm{d}_{\mathrm{Acetaldeído}}\left[\text { Acetaldeído }_{\mathrm{e}}-\text { Acetaldeído }_{\mathrm{d}}\left(1-\frac{1}{\mathrm{Rd}}\right)\right] 10^{-6} \\
& \text { Formaldeído }_{\mathrm{M}}=\mathrm{v}_{\mathrm{ed}} \cdot \mathrm{d}_{\text {Formaldeído }}\left[\text { Formaldeído }_{\mathrm{e}}-\text { Formaldeído }_{\mathrm{d}}\left(1-\frac{1}{\mathrm{Rd}}\right)\right] 10^{-6}
\end{aligned}
$$

Uma vez obtendo os valores de massa em gramas por fase de um dado componente do gás de escapamento de veículos rodoviários automotores leves no ciclo de condução urbano completo, basta utilizar a relação abaixo para calcular a emissão ponderada correspondente (Equação 10). [8]

$Y_{M P}=0,43\left(\frac{Y_{T F}+Y_{E}}{D_{T F}+D_{E}}\right)+0,57\left(\frac{Y_{T Q}+Y_{E}}{D_{T Q}+D_{E}}\right)$

(Equação 10)

Onde,

$\mathrm{Y}_{\mathrm{MP}} \rightarrow$ Emissão ponderada de cada componente do gás emitido, em [g/km];

$\mathrm{Y} \rightarrow$ Emissão em massa de cada componente do gás emitido em uma dada fase do ciclo, em [g], com exceção do subscrito "MP”;

$\mathrm{D} \rightarrow$ Distância percorrida pelo veículo, medida durante uma dada fase do ciclo, em [km], com exceção do subscrito "MP";

$$
\begin{aligned}
& \mathrm{TF}_{\mathrm{E}} \rightarrow \text { Subscrito referente à fase transitória com partida a frio; } \\
& \rightarrow \text { Subscrito referente à fase estabilizada; }
\end{aligned}
$$


$\mathrm{TQ} \rightarrow$ Subscrito referente à fase transitório com partida a quente.

3.2. Fator MIR aplicado à massa ponderada de composto orgânico reativo

As Equações 11 e 12 representam, de maneira genérica, o somatório das massas ponderadas dos componentes do gás de escapamento de veículos rodoviários automotores leves em ensaios no ciclo de condução urbano completo, em sua forma reduzida e expandida, respectivamente, em gramas por quilômetro. [8]

$$
\begin{aligned}
\sum_{n}^{\mathrm{i}} \mathrm{Y}_{\mathrm{MPn}}=\sum_{\mathrm{n}}^{\mathrm{i}} 0,43\left(\frac{\mathrm{Y}_{\mathrm{TFn}}+\mathrm{Y}_{\mathrm{En}}}{\mathrm{D}_{\mathrm{TFn}}+\mathrm{D}_{\mathrm{En}}}\right)+0,57\left(\frac{\mathrm{Y}_{\mathrm{TQn}}+\mathrm{Y}_{\mathrm{En}}}{\mathrm{D}_{\mathrm{TQn}}+\mathrm{D}_{\mathrm{En}}}\right) \\
\sum_{\mathrm{n}}^{\mathrm{i}} \mathrm{Y}_{\mathrm{MPn}}=\left[0,43\left(\frac{\mathrm{Y}_{\mathrm{TF} 1}+\mathrm{Y}_{\mathrm{E} 1}}{\mathrm{D}_{\mathrm{TF} 1}+\mathrm{D}_{\mathrm{E} 1}}\right)+0,57\left(\frac{\mathrm{Y}_{\mathrm{TQ} 1}+\mathrm{Y}_{\mathrm{E} 1}}{\mathrm{D}_{\mathrm{TQ} 1}+\mathrm{D}_{\mathrm{E} 1}}\right)\right]+\cdots \\
+\left[0,43\left(\frac{\mathrm{Y}_{\mathrm{TFn}}+\mathrm{Y}_{\mathrm{En}}}{\mathrm{D}_{\mathrm{TFn}}+\mathrm{D}_{\mathrm{En}}}\right)+0,57\left(\frac{\mathrm{Y}_{\mathrm{TQn}}+\mathrm{Y}_{\mathrm{En}}}{\mathrm{D}_{\mathrm{TQn}}+\mathrm{D}_{\mathrm{En}}}\right)\right]
\end{aligned}
$$

Conhecendo-se a definição do fator MIR fornecida na seção 2, este deve ser aplicado à massa de qualquer composto orgânico reativo, ROC (não deve ser empregado em termos de concentração), convertendo a Equação 12 na Equação 13.[8,11]

$$
\begin{aligned}
& \left(\text { Potencial }_{\mathrm{O}_{3}}\right)_{\mathrm{MP}}=\sum_{\mathrm{n}}^{\mathrm{i}} \mathrm{Y}_{\mathrm{MPn}} \cdot \mathrm{MIR}_{\mathrm{n}}= \\
& {\left[0,43\left(\frac{\mathrm{MIR}_{1} \cdot \mathrm{Y}_{\mathrm{TF} 1}+\mathrm{MIR}_{1} \cdot \mathrm{Y}_{\mathrm{E} 1}}{\mathrm{D}_{\mathrm{TF} 1}+\mathrm{D}_{\mathrm{E} 1}}\right) 0,57\left(\frac{\mathrm{MIR}_{1} \cdot \mathrm{Y}_{\mathrm{TQ} 1}+\mathrm{MIR}_{1} \cdot \mathrm{Y}_{\mathrm{E} 1}}{\mathrm{D}_{\mathrm{TQ} 1}+\mathrm{D}_{\mathrm{E} 1}}\right)\right]+\cdots} \\
& +\left[0,43\left(\frac{\mathrm{MIR}_{\mathrm{n}} \cdot \mathrm{Y}_{\mathrm{TFn}}+\mathrm{MIR}_{\mathrm{n}} \cdot \mathrm{Y}_{\mathrm{En}}}{\mathrm{D}_{\mathrm{TFn}}+\mathrm{D}_{\mathrm{En}}}\right)+0,57\left(\frac{\mathrm{MIR}_{\mathrm{n}} \cdot \mathrm{Y}_{\mathrm{TQn}}+\mathrm{MIR}_{\mathrm{n}} \cdot \mathrm{Y}_{\mathrm{En}}}{\mathrm{D}_{\mathrm{TQn}}+\mathrm{D}_{\mathrm{En}}}\right)\right]
\end{aligned}
$$

Podem-se agrupar os fatores MIR de cada um dos componentes da Equação 13 originado a Equação 14, ou seja, os fatores MIR também podem ser aplicados diretamente aos valores de massa ponderada. $[8,11]$

$$
\begin{aligned}
& \left(\text { Potencial }_{\mathrm{O}_{3}}\right)_{\mathrm{MP}}=\sum_{\mathrm{n}}^{\mathrm{i}} \mathrm{ROC}_{\mathrm{MPn}} \cdot \mathrm{MIR}_{\mathrm{n}}=\sum_{\mathrm{n}}^{\mathrm{i}} \mathrm{Y}_{\mathrm{MPn}} \cdot \mathrm{MIR}_{\mathrm{n}}= \\
& \operatorname{MIR}_{1}\left[0,43\left(\frac{\mathrm{Y}_{\mathrm{TF} 1}}{\mathrm{D}_{\mathrm{TF} 1}+\mathrm{Y}_{\mathrm{E} 1}}\right) 0,57\left(\frac{\mathrm{Y}_{\mathrm{TQ} 1}+\mathrm{Y}_{\mathrm{E} 1}}{\mathrm{D}_{\mathrm{TQ} 1}+\mathrm{D}_{\mathrm{E} 1}}\right)\right]+\cdots \\
& \quad+\mathrm{MIR}_{\mathrm{n}}\left[0,43\left(\frac{\mathrm{Y}_{\mathrm{TFn}}+\mathrm{Y}_{\mathrm{En}}}{\mathrm{D}_{\mathrm{TFn}}+\mathrm{D}_{\mathrm{En}}}\right)+0,57\left(\frac{\mathrm{Y}_{\mathrm{TQn}}+\mathrm{Y}_{\mathrm{En}}}{D_{\mathrm{TQn}}+\mathrm{D}_{\mathrm{En}}}\right)\right]
\end{aligned}
$$

A aplicação dos fatores MIR diretamente aos valores de massa ponderada de cada um dos compostos orgânicos reativos é mais simples e prática, pois utiliza os valores finais de cada poluente descritos nos procedimentos citados na seção 3.1, não havendo necessidade de grandes alterações nas planilhas de cálculo dos laboratórios de emissão veicular, LEV.

3.3. Obtenção de NMOG e seu potencial de formação de ozônio 
Aplicando a Equação 14aosROC das emissões de gás de escapamento de veículos automotores, obtém-se a Equação 15. [11]

$$
\begin{aligned}
\left(\text { Potencial }_{\mathrm{O}_{3}}\right)_{\mathrm{MP}} & \\
& =\left(\mathrm{NONMHC}_{\mathrm{MP}} \cdot \mathrm{MIR}_{\mathrm{NONMHC}}\right)+\left(\mathrm{COH}_{\mathrm{MP}} \cdot \mathrm{MIR}_{\mathrm{COH}}\right) \\
& +\left(\mathrm{CHO}_{\mathrm{MP}} \cdot \mathrm{MIR}_{\mathrm{CHO}}\right)+\left(\mathrm{CH}_{4 \mathrm{MP}} \cdot \mathrm{MIR}_{\mathrm{CH}_{4}}\right)+\left(\mathrm{CO}_{\mathrm{MP}} \cdot \mathrm{MIR}_{\mathrm{CO}}\right)
\end{aligned}
$$

Conhecendo-se os valores do fator MIR dos principais compostos presentes na emissão de escapamento de veículos rodoviários automotores leves quando se utiliza etanol hidratado combustível (seção 2.2), pode-se escrever a Equação 16.[11]

$$
\begin{aligned}
\left(\text { Potencial }_{\mathrm{O}_{3}}\right)_{\mathrm{MP}} & \\
& =\left(\mathrm{NONMHC}_{\mathrm{MP}} \cdot \mathrm{MIR}_{\mathrm{NONMHC}}\right)+\left(\mathrm{ETOH}_{\mathrm{MP}} \cdot \mathrm{MIR}_{\mathrm{ETOH}}\right) \\
& +\left(\text { Acetaldeído }_{\mathrm{MP}} \cdot \mathrm{MIR}_{\text {Acetaldeído }}+\mathrm{CHO}_{\mathrm{Formaldeído}}\right. \\
& \left.\cdot \mathrm{MIR}_{\text {Formaldeído }}\right)+\left(\mathrm{CH}_{4 \mathrm{MP}} \cdot \mathrm{MIR}_{\mathrm{CH}_{4}}\right)+\left(\mathrm{CO}_{\mathrm{MP}} \cdot \mathrm{MIR}_{\mathrm{CO}}\right)
\end{aligned}
$$

Sabendo-se que o $\quad \mathrm{MIR}_{\mathrm{CH}_{4}}$ é de $0,028 \quad\left[\begin{array}{lllllll}\mathrm{g} & \mathrm{O}_{3} / \mathrm{g} & \mathrm{CH}_{4}\end{array}\right]$ e o $\mathrm{MIR}_{\mathrm{CO}}$ é de 0,056 [g $\mathrm{g}_{3} / \mathrm{g} \mathrm{CO}$ ], pode-se considerar que as contribuições destes gases são nulas, originando a Equação 17 (as massas ponderadas destes poluentes são relativamente baixas quando comparadas aos demais ROC).[11]

$$
\begin{aligned}
& \left(\text { Potencial }_{\mathrm{O}_{3}}\right)_{\mathrm{MP}}=\mathrm{NMOG}_{\mathrm{MP}} \cdot \mathrm{MIR}_{\mathrm{NMOG}} \\
& =\left(\mathrm{NONMHC}_{\mathrm{MP}} \cdot \mathrm{MIR}_{\mathrm{NONMHC}}\right)+\left(\mathrm{ETOH}_{\mathrm{MP}} \cdot \mathrm{MIR}_{\mathrm{ETOH}}\right) \\
& +\left(\text { Acetaldeído } \mathrm{MP}_{\mathrm{MP}} \cdot \mathrm{MIR}_{\text {Acetaldeído }}+\mathrm{CHO}_{\text {Formaldeído }} \cdot \mathrm{MIR}_{\mathrm{Formaldeído}}\right)
\end{aligned}
$$

Onde,

$$
\mathrm{NONMHC}_{\mathrm{M}}=\mathrm{NMHC}_{\mathrm{M}}-\mathrm{d}_{\mathrm{HC}} \sum_{\mathrm{n}}^{\mathrm{i}} \frac{\mathrm{COH}_{\mathrm{M}}}{\mathrm{d}_{\mathrm{COH}}} \cdot \mathrm{Fr}_{\mathrm{COH}}-\mathrm{d}_{\mathrm{HC}} \sum_{\mathrm{n}}^{\mathrm{i}} \frac{\mathrm{CHO}_{\mathrm{M}}}{\mathrm{d}_{\mathrm{CHO}}} \cdot \mathrm{Fr}_{\mathrm{CHO}}
$$

A Equação 17 equivale a Equação 15, porém deixando explícito que os componentes do lado direito do sinal da igualdade são exatamente os compostos que constituem os NMOG, portanto, conhecendo-se os valores massa ponderada de NMOG (Equação 01) e dos parâmetros do lado direito do sinal da igualdade da Equação 17, pode-se estimar um valor de MIR $_{\text {NMOG }}$ médio e utilizar este para auxiliar na definição de limites máximos de emissão de NMOG.[11]

$\mathrm{NMOG}_{\mathrm{MP}} \cdot \mathrm{MIR}_{\mathrm{NMOG}}=\left(\mathrm{NONMHC}_{\mathrm{MP}} \cdot \mathrm{MIR}_{\mathrm{NONMHC}}\right)+\left(\mathrm{ETOH}_{\mathrm{MP}} \cdot \mathrm{MIR}_{\mathrm{ETOH}}\right)$

$+\left(\right.$ Acetaldeído $\left.\mathrm{MP}_{\mathrm{MP}} \cdot \mathrm{MIR}_{\text {Acetaldeído }}+\mathrm{CHO}_{\text {Formaldeído }} \cdot \mathrm{MIR}_{\mathrm{Formaldeído}}\right)$

(Equação 19)

Portanto, como relatado na seção 2, os valores de fatores MIR apenas seriam utilizados para estimar os limites máximos de emissão NMOG (no cálculo de NMOG há apenas parâmetros relacionados às emissões ponderadas de seus componentes).

Pode-se simplificar a Equação 18 conhecendo-se quais os principais compostos da classe dos alcoóis (Equação 20) e compostos carbonílicos (Equação 21) estão presentes na emissão de escapamento de veículos rodoviários automotores leves quando se utiliza etanol hidratado combustível, resultando na Equação 22. 


$$
\begin{aligned}
& \sum_{\mathrm{n}}^{\mathrm{i}} \frac{\mathrm{COH}_{\mathrm{M}}}{\mathrm{d}_{\mathrm{COH}}} \cdot \mathrm{Fr}_{\mathrm{COH}}=\frac{\mathrm{ETOH}_{\mathrm{M}}}{\mathrm{d}_{\mathrm{ETOH}}} \cdot \mathrm{Fr}_{\mathrm{ETOH}} \\
& \sum_{\mathrm{n}}^{\mathrm{i}} \frac{\mathrm{CHO}_{\mathrm{M}}}{\mathrm{d}_{\mathrm{CHO}}} \cdot \mathrm{Fr}_{\mathrm{CHO}}=\frac{\text { Acetaldeído }_{\mathrm{M}}}{\mathrm{d}_{\text {Acetaldeído }}} \cdot \mathrm{Fr}_{\text {Acetaldeído }}+\frac{\text { Formaldeído }_{\mathrm{M}}}{\mathrm{d}_{\text {Formaldeído }}} \cdot \mathrm{Fr}_{\text {Formaldeído }} \\
& \text { NONMHC }=\mathrm{NMHC}_{M}-\mathrm{d}_{\mathrm{HC}} \frac{\mathrm{ETOH}_{\mathrm{M}}}{\mathrm{d}_{\mathrm{ETOH}}} \cdot \mathrm{Fr}_{\mathrm{ETOH}} \\
& -\mathrm{d}_{\mathrm{HC}}\left(\frac{\text { Acetaldeído }_{\mathrm{M}}}{\mathrm{d}_{\text {Acetaldeído }}} \cdot \mathrm{Fr}_{\text {Acetaldeído }}+\frac{\text { Formaldeído }_{\mathrm{M}}}{\mathrm{d}_{\text {Formaldeído }}} \cdot \mathrm{Fr}_{\text {Formaldeído }}\right)
\end{aligned}
$$

Portanto, pode-se substituir a Equação 22 na Equação 17 para calcular o potencial de formação de ozônio dos NMOG (Equação 23).

$$
\begin{aligned}
& \left(\text { Potencial }_{\mathrm{O}_{3}}\right)_{\mathrm{MP}}= \\
& {\left[\left(\mathrm{NMHC}_{\mathrm{M}}-\mathrm{d}_{\mathrm{HC}} \sum_{\mathrm{n}}^{\mathrm{i}} \frac{\mathrm{COH}_{\mathrm{M}}}{\mathrm{d}_{\mathrm{COH}}} \cdot \mathrm{Fr}_{\mathrm{COH}}-\mathrm{d}_{\mathrm{HC}} \sum_{\mathrm{n}}^{\mathrm{i}} \frac{\mathrm{CHO}_{\mathrm{M}}}{\mathrm{d}_{\mathrm{CHO}}} \cdot \mathrm{Fr}_{\mathrm{CHO}}\right)_{\mathrm{MP}} \cdot \mathrm{MIR}_{\mathrm{NONMHC}}\right]} \\
& +\left(\mathrm{ETOH}_{\mathrm{MP}} \cdot \mathrm{MIR}_{\mathrm{ETOH}}\right)+\left(\mathrm{CHO}_{\mathrm{MP}} \cdot \mathrm{MIR}_{\mathrm{CHO}}\right)
\end{aligned}
$$

Dados de literatura fornecidos pela Tabela 04 mostram alguns exemplos dos fatores de resposta de ROC do DIC dos analisadores de HC de emissões dos gases de escapamento de veículos automotores.[11]

Tabela 04. Exemplos de fatores de resposta do DIC para os compostos NONMHC.

\begin{tabular}{ccccc}
\hline $\mathbf{F r}_{\text {NONMHC }} \frac{[\mathbf{p p m C}]}{[\mathbf{p p m C}]}$ & $\mathbf{C H}_{\mathbf{4}}$ & ETOH & Acetaldeído & Formaldeído \\
\hline
\end{tabular}

Os dados de fatores de resposta de metano e etanol do DIC fornecidos pela Tabela 04 são muito próximos dos valores encontrados nos LEV brasileiros, sendo os valores teóricos adotados provindos destes de 1,12 e 0,75 , respectivamente.[11]

Já os fatores de resposta de acetaldeído e formaldeídos do DIC ainda não possuem valores medidos oficialmente no Brasil para comparação. No futuro próximo, estes fatores podem ter seus valores comparados, pois já existem empresas acreditadas pelo INMETRO que fornecem estes gases considerados especiais, possibilitando o cálculo dos parâmetros relacionados aos NONMHC e NMOG.

\section{LEVANTAMENTO DE INFORMAÇÕES SOBRE VEÍCULOS FLEX}

Por meio de dados de processos de homologação de veículos flex 2010 e 2011 analisados criticamente foi possível realizar as seguintes discussões (a grande maioria dos dados se refere aos veículos leves de passageiros):

\subsection{Aldeídos [16]}

Os gráficos das Figuras 04 e 05 mostram que ensaios realizados utilizando os combustíveis gasool A22 referência e EHR emitem proporcionalmente mais 
acetaldeído do que formaldeído quando se compara os componentes de aldeídos totais, $\mathrm{CHO}$, contidos no gás de escapamento.

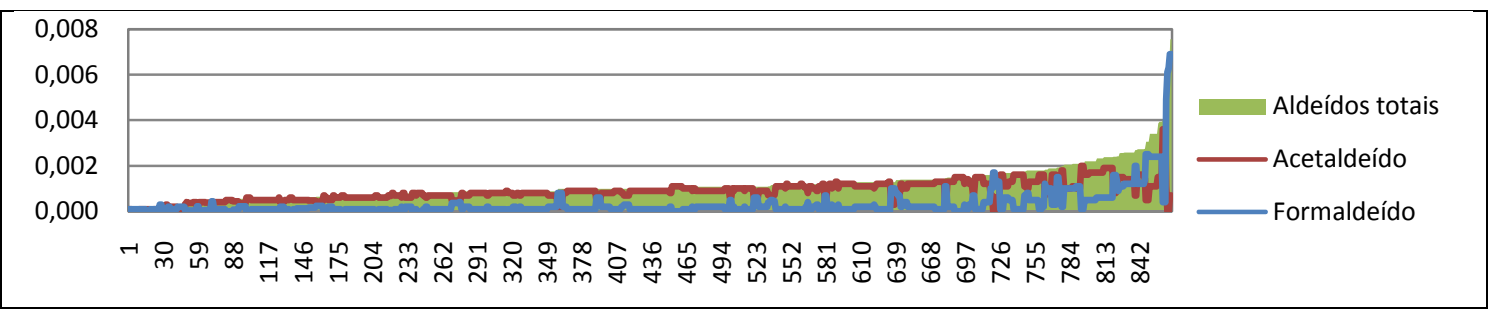

Figura 04. Gráficos das emissões ponderadas de aldeídoscontidos no gás de escapamento em ensaios realizados com gasool A22 referência, dados em $[\mathrm{g} / \mathrm{km}]$.

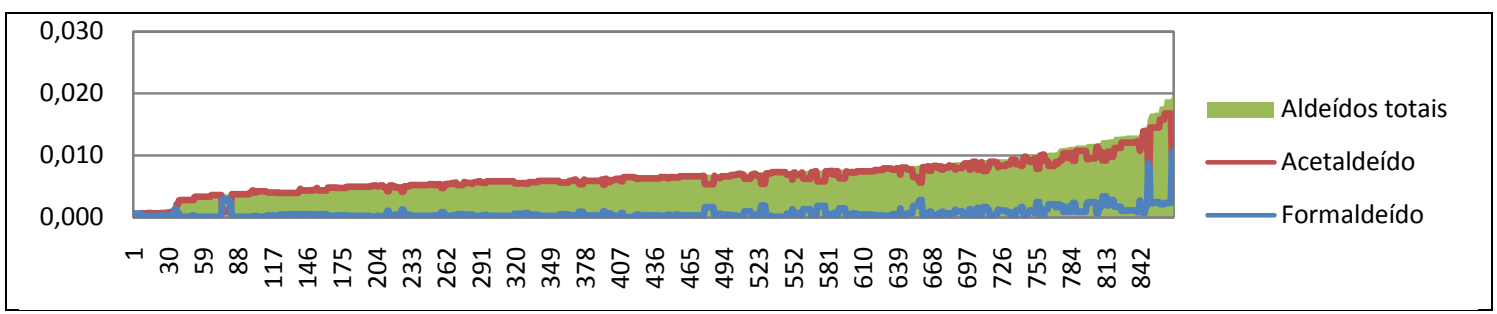

Figura 05. Gráficos das emissões ponderadas de aldeídos contidos no gás de escapamento em ensaios realizados com EHR, dados em [g/km].

Dos 869 ensaios analisados, apenas os resultados de um ensaiofoi excluído do gráfico da Figura 04, sendo o valor numérico de aldeídos totais igual a 0,012 g/km, para melhor visualização dos demais dados, enquanto nenhum resultado foi excluído do gráfico da Figura 05.

Também pode observar que não há valores de emissão ponderada de aldeídos totais contidos no gás de escapamento, quando se utiliza gasool A22 referência, maiores do que $0,010 \mathrm{~g} / \mathrm{km}$, Figura 04, com exceção do resultado anômalo relatado, ou seja, os resultados de emissão ponderada de aldeídos totais estão abaixo da metade do valor vigente e futuro do respectivo limite de emissão máxima (Tabela 05).

Tabela 05. Limites vigentes e futuros de limites máximos de emissão ponderada de aldeídos totais, $\mathrm{CHO}_{\mathrm{MP}}$, de veículos leves.

\begin{tabular}{cccc}
\hline $\begin{array}{c}\text { Limites máximos de } \\
\text { emissão de CHO }\end{array}$ & $\begin{array}{c}\text { Veículos Leves de } \\
\text { Passageiros }\end{array}$ & $\begin{array}{c}\text { Veículos Leves } \\
\text { Comerciais } \\
\mathbf{M} \leq \mathbf{1 7 0 0} \mathbf{~ k g}\end{array}$ & $\begin{array}{c}\text { Veículos Leves } \\
\text { Comerciais } \\
\mathbf{M}>\mathbf{1 7 0 0} \mathbf{~ k g}\end{array}$ \\
\hline Fase L5 (Vigente) & 0,02 & 0,02 & 0,04 \\
Fase L6 & 0,02 & 0,02 & 0,03 \\
\hline
\end{tabular}

Já os dados fornecidos pela Figura 05 permitem concluir que apenas 15,65\% dos ensaios com EHR possuem resultados de emissão ponderada de aldeídos totais contido no gás de escapamento maiores do que $50 \%$ dos respectivos limites máximos vigentes e futuros, descritos pela Tabela 1 (ensaios de número 734 a 869).

É interessante notar, pelos gráficos das Figuras 06 e 07, que a emissão predominante de aldeídos totais em gramas por quilômetro quando se analisa cada uma das fases do ciclo de condução urbano completo se processa na fase 1 , tanto em ensaios de 
veículos flex abastecidos com gasool A22 referência como abastecidos com EHR (as curvas referentes às fases 2 e 3 possuem uma intensidade relativamente baixa).

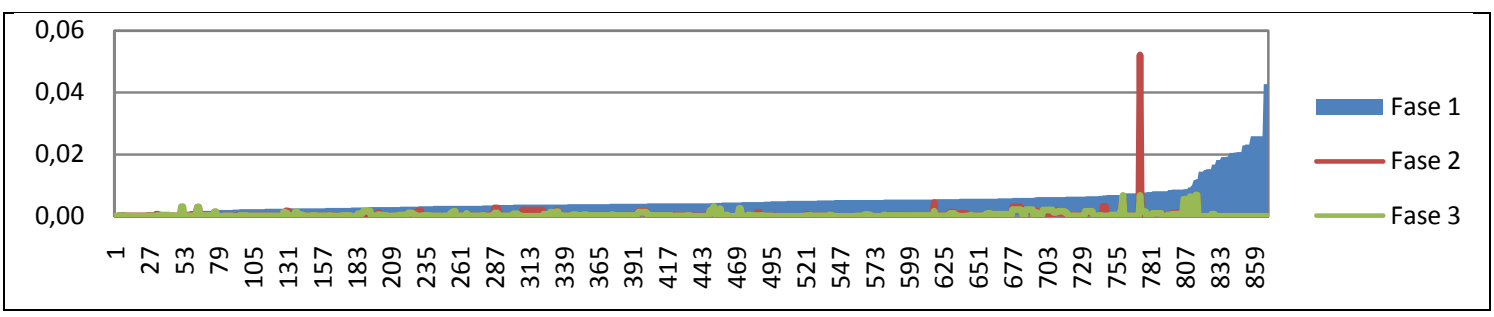

Figura 06. Gráficos das emissões por fase do ciclo de condução urbano completo de aldeídos totais contidos no gás de escapamento em ensaios realizados com gasool A22 referência, dados em [g/km].

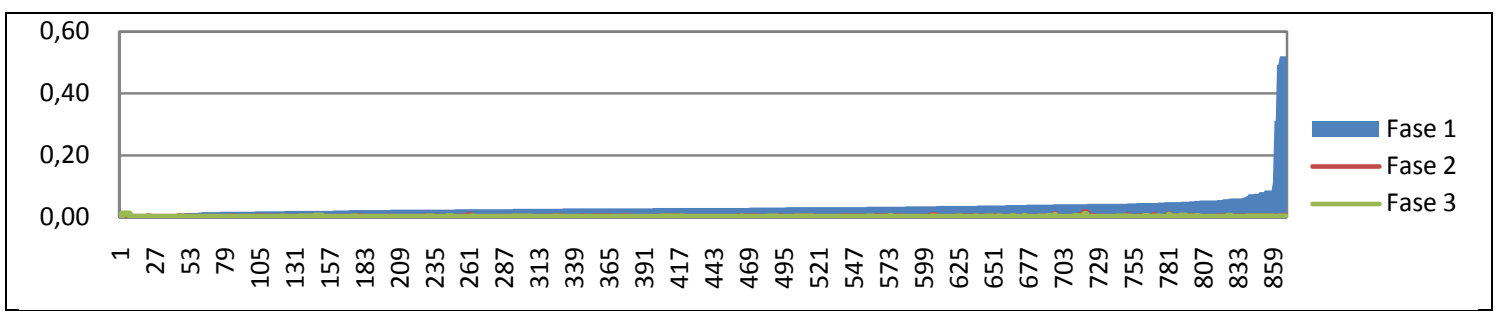

Figura 07. Gráfico das emissões por fase do ciclo de condução urbano completo de aldeídos totais contidos no gás de escapamento em ensaios realizados com EHR, dados em $[\mathrm{g} / \mathrm{km}]$.

Os dados apresentados pela Figura 06 indicam que diferença de porcentagem média das emissões de aldeídos totais da fase 2 em relação à fase 1 é de 97,2 \% (mediana de $98,7 \%$ ), enquanto a porcentagem média da fase 3 em relação à fase 1 é de 98,0 \% (mediana de 99,2\%), eliminado-se apenas seis dados anômalos (correspondentes a $0,69 \%$ ), para ensaios com gasool A22 referência.

Já os dados apresentados pela Figura 07 indicam que a diferença de porcentagem média das emissões de aldeídos totais da fase 2 em relação à fase 1 é de 89,56 \% (mediana de 96,00\%), enquanto a porcentagem média da fase 3 em relação à fase 1 é de 90,32 \% (mediana de 94,55 \%), eliminado-se também apenas seis dados anômalos (correspondentes a 0,69\%), para ensaios com EHR. Neste caso, os valores de mediana são mais significativos, pois ocorre maior dispersão de resultados em ensaios com baixa emissão de aldeídos totais durante a fase 1 (cem primeiros ensaios).

Para avaliar a proporção da emissão ponderada de acetaldeído e formaldeído em veículos flex abastecidos com gasool A22 referência e EHR, construíram-se os gráficos das Figuras 08 e 09. 


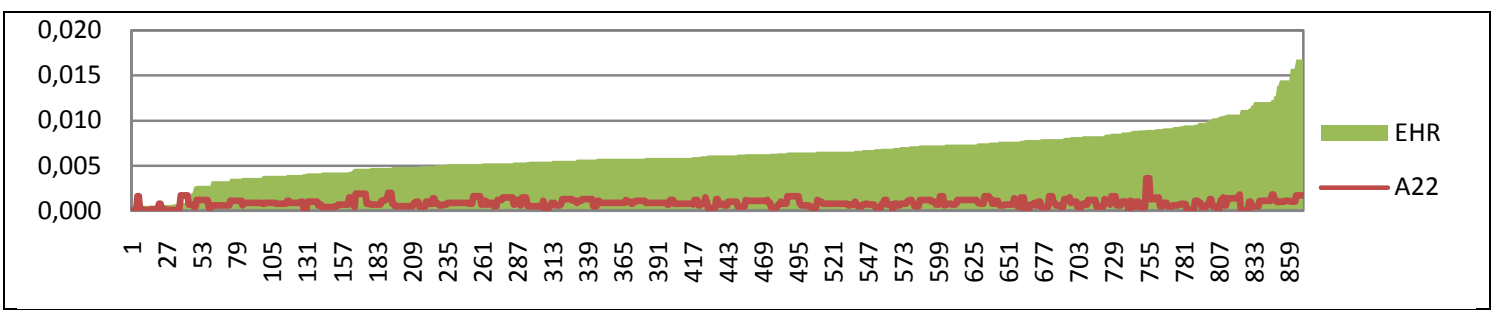

Figura 08. Gráfico das emissões ponderadas de acetaldeído contido no gás de escapamento em ensaios realizados com gasool A22 referência e EHR, dados em $[\mathrm{g} / \mathrm{km}]$.

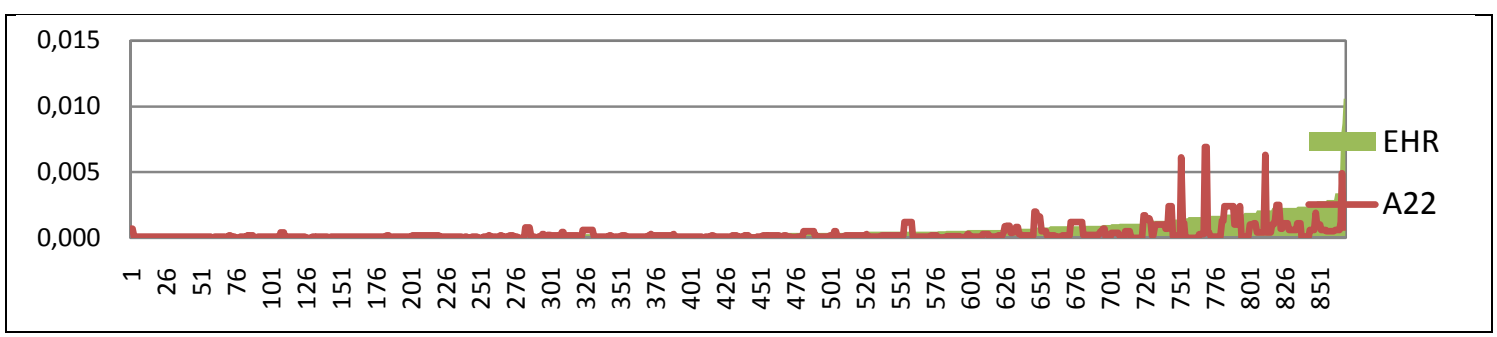

Figura 09. Gráfico das emissões ponderadas de formaldeído contido no gás de escapamento em ensaios realizados com gasool A22 referência e EHR, dados em $[\mathrm{g} / \mathrm{km}]$.

Os gráficos da Figura 05 evidenciam que a emissão ponderada de acetaldeído no gás de escapamento de veículos flex abastecidos com EHR é muito superior a emissão deste poluente quando os mesmo veículos são abastecidos com gasool A22 referência, sendo a diferença média de $85,05 \%$ e a mediana de $86,21 \%(98,39 \%$ dos ensaios), eliminando-se $1,15 \%$ dos resultados associados aos casos onde a emissão de ensaios com EHR é menor do que gasool A22 (dez dos 869 ensaios analisados) e $0,46 \%$ dos ensaios que possuem o mesmo resultado independente do combustível utilizado.

Já os gráficos da Figura 09 exibemvalores mais próximos de emissão ponderada de formaldeído no gás de escapamento de veículos flex abastecidos com EHR e gasool A22 referência quando comparado ao acetaldeído, porém, ainda possuem a maior parte das emissões relacionadas ao EHR, cerca de 76,52 \% dos ensaios, com um valor de diferença média de $65,92 \%$ e mediana de $66,67 \%$.

Dos ensaios restantes, $13,81 \%$ possuem valores iguais de emissão ponderada de formaldeído independente do combustível utilizado e 9,67 \% possuem maiores emissões ponderadas de formaldeído para ensaios realizado com gasool A22 referência quando comparado ao EHR (estes possuem grande variação entre os resultados).

\subsection{Metano [16]}

Os gráficos da Figura 10 indicam que a emissão ponderada de metano, $\mathrm{CH}_{4 \mathrm{MP}}$, em ensaios realizados em veículos flex utilizando os combustíveis gasool A22 referência e EHR possuem diferenças significativas. 


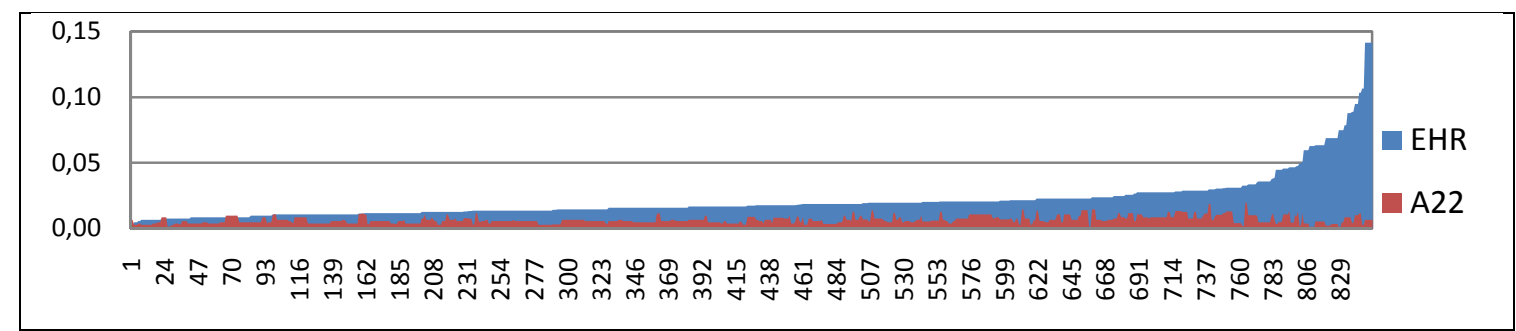

Figura 10. Gráficos de $\mathrm{CH}_{4 \mathrm{MP}}$ contido no gás de escapamento em ensaios realizados com EHR e gasool A22 referência, dados em [g/km].

Dos 851 ensaios relatados nos gráficos da Figura 07, o que corresponde a 97,88\% dos ensaios, 833 possuem valores de $\mathrm{CH}_{4 \mathrm{MP}}$ superiores quando executados com EHR em relação ao gasool A22 referência, apresentando uma diferença percentual média de $61,77 \%$ e mediana de $62,50 \%$.

Dos ensaios restantes, $1,76 \%$ possuem emissões de $\mathrm{CH}_{4 \mathrm{MP}}$ superiores quando se utiliza gasool A22 referência em relação ao EHR, porém são resultados com grande variância (15 de 851 ensaios) e apenas três ensaios que apresentam o mesmo resultado independente do combustível ( $0,35 \%$ dos ensaios).

Agrupando-se o número de ensaios relativos aos 833 valores restantes do gráfico da Figura 10 em intervalos de 10 unidades de porcentagem correspondentes a diferença percentual de $\mathrm{CH}_{4 \mathrm{MP}}$ em ensaios abastecidos com gasool A22 referência e EHR em veículos leves, obtém-se o gráfico populacional fornecido pela Figura 11 - A e sua versão em termos de porcentagem populacional, Figura 11 B.Deste modo, se conhece quais intervalos de diferenças percentuais contribuem mais para cada tipo de combustível.

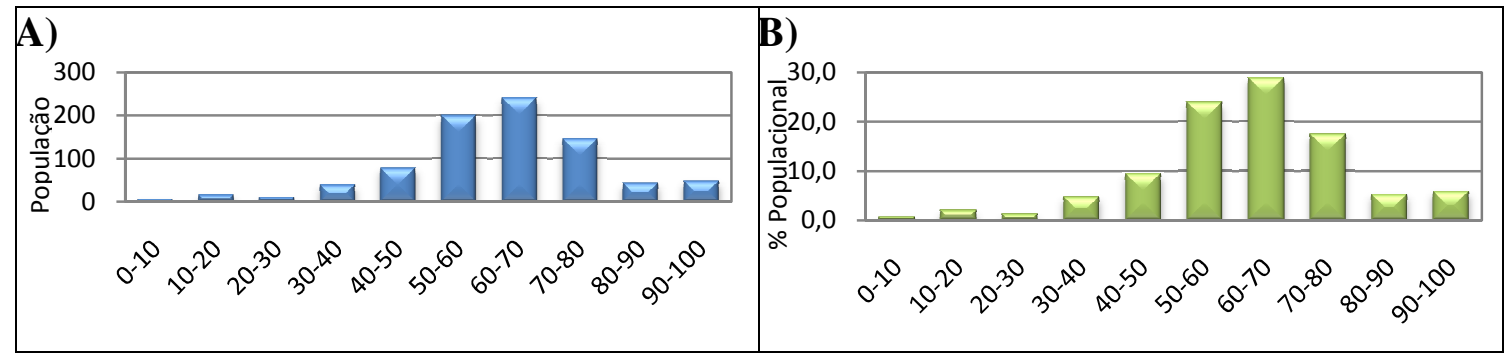

Figura 11.A) Gráfico populacional e de B) Porcentagem populacional das diferenças percentuais de $\mathrm{CH}_{4 \mathrm{MP}}$ em ensaios realizados com gasool A22 referência e EHR em veículos leves em intervalos de dez por cento.

O gráfico da Figura 12 fornece as médias das diferenças percentuais dos ensaios dos intervalos exibidos pela Figura 08.

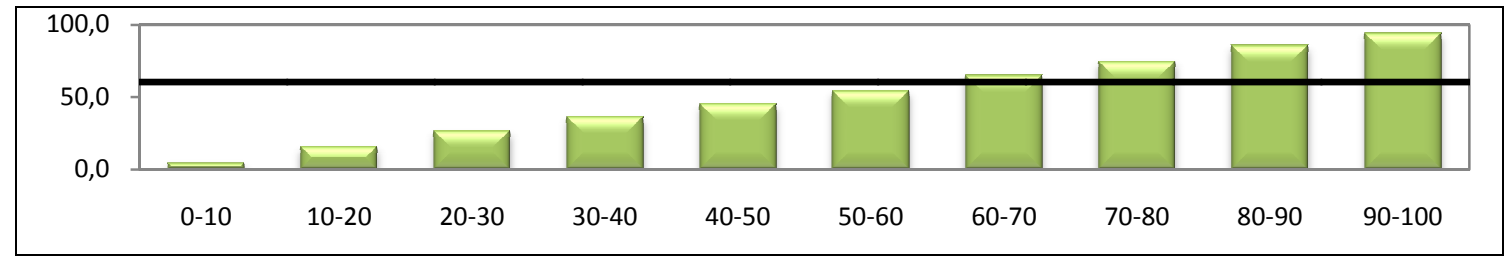

Figura 12. Gráfico das médias das diferenças percentuais deCH $\mathrm{H}_{4 \mathrm{MP}} \mathrm{em}$ ensaios realizados com gasool A22 referência e EHR em veículos leves em intervalos de dez por cento. 
A análise conjunta dos gráficos da Figura 11 - A e B permite observar que os intervalos que serão mais representativos são os compreendidos entre 50 e $80 \%$ das populações de dados.

A média ponderada dos dados fornecidos pelas Figuras 11 e 12 comprova o descrito no parágrafo anterior, pois esta resulta em uma diferença percentual de cerca 60,47\% (linha preta da Figura 12).

Resultados da literatura indicam que tanto ensaios em veículos flex com gasolinae combustível E85, como ensaios realizados em veículos flex com combustível E85 e equivalentes dedicados à gasolina, emitem o dobro da emissão de metano quando abastecidos com E85 em relação à gasolina (combustível americano), estando de acordo com os resultados discutidos neste artigo.

Apesar do metano não possuir limite máximo de emissão controlado pelo PROCONVE, com exceção do controle indireto para veículos alimentados com GNV, as informações discutidas nesta seção possuem grande importância, pois o metano é um dos gases que mais contribuem para o efeito estufa, segundo o potencial de aquecimento global, GWP - Global Warming Potential (Tabela 06).

Tabela 06. Dados de potencial de aquecimento global, GWP, para o dióxido de carbono, metano, óxido nitroso, HFC-134 e HFC-23.

\begin{tabular}{ccccc}
\hline Espécie & $\begin{array}{c}\text { Tempo de } \\
\text { vida }[\text { anos] }\end{array}$ & $\mathbf{2 0}$ anos & 100 anos & 500 anos \\
\hline Dióxido de carbono & Variável & 1 & 1 & 1 \\
Metano & $\underline{\mathbf{1 2} \pm \mathbf{3}}$ & $\underline{\mathbf{5 6}}$ & $\underline{\mathbf{2 1}}$ & $\underline{\mathbf{6 , 5}}$ \\
Óxido nitroso & 120 & 280 & 310 & 170 \\
HFC-134 & 10,6 & 2900 & 1000 & 310 \\
HFC-23 & 264 & 9100 & 11700 & 9800 \\
\hline
\end{tabular}

A Tabela 06 mostra quão grande é contribuição do metano comparando-se este a grandes vilões do aquecimento global, como o óxido nitroso e os HCF (o GWP é uma medida relativa de como uma determinada quantidade de gás do efeito estufacontribui para o aquecimento global, tendo como referencial odióxido de carbono, cujo potencial é definido como 1).

\subsection{Etanol[16]}

Os gráficos da Figura 13 indicam as emissões ponderadas de ETOH, hidrocarbonetos não metano com desconto de etanol,(NMHC-ETOH) $)_{M P}$, e $\mathrm{CH}_{4}$ em ensaios realizados com veículos flex utilizando EHR.

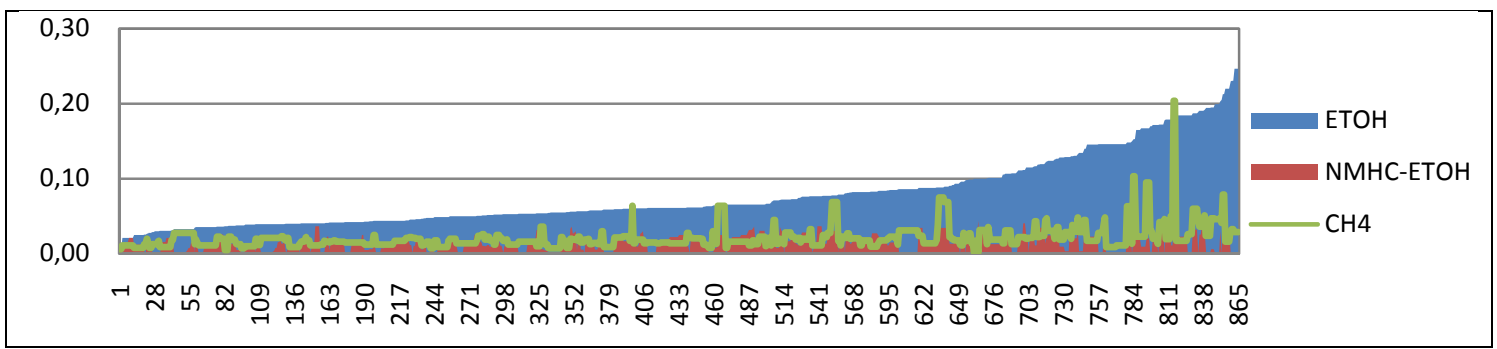

Figura 13. Gráfico das $\mathrm{ETOH}_{\mathrm{MP}}$, $(\mathrm{NMHC}-\mathrm{ETOH})_{\mathrm{MP}}$ e $\mathrm{CH}_{4 \mathrm{MP}}$ contidos no gás de escapamento em ensaios realizados com EHR, dados em $[\mathrm{g} / \mathrm{km}]$. 
Apesar da Figura 13 exibir emissões ponderadas de diferentes poluentes, e por esse motivo estas não podem ser comparadas diretamente, esta figurafornece a dimensão da grande emissão de etanol por escapamento dos veículos flex ao meio ambiente, frente aos hidrocarbonetos (lembrar que cada um destes poluentes possuem densidades diferentes).

Os gráficos da Figura 14são semelhantes aos da Figura 13, porém aplicando um fator de resposta de metano do DIC teórico, $\mathrm{Fr}_{\mathrm{CH}_{4}}$, de 1,12.

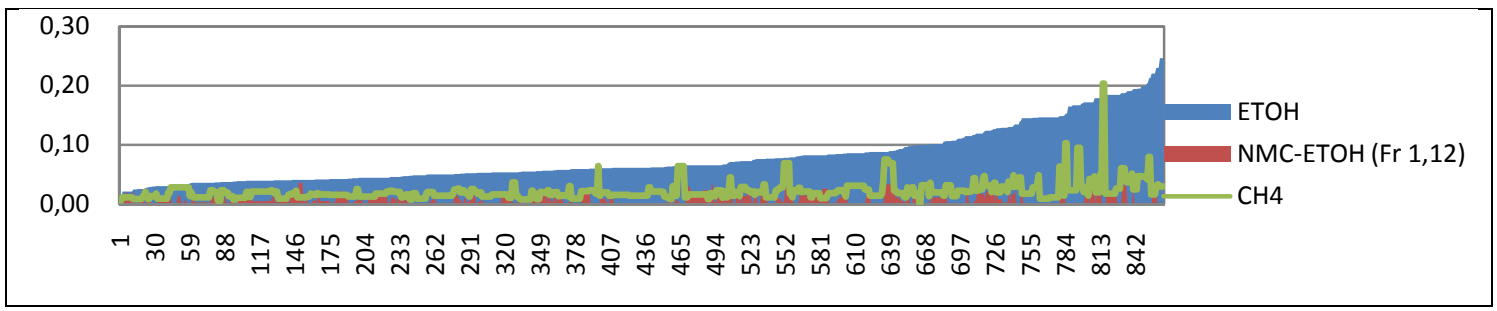

Figura 14. Gráfico das $\mathrm{ETOH}_{\mathrm{MP}}$, $(\mathrm{NMHC}-\mathrm{ETOH})_{\mathrm{MP}}$ com $\mathrm{Fr} 1,12, \mathrm{e} \mathrm{CH}_{4 \mathrm{MP}}$ contidos no gás de escapamento em ensaios realizados com EHR, dados em [g/km].

A comparação das curvas NMHC-ETOH da Figura 13 e NMHC-ETOH (Fr 1,12) da Figura 14 (curvas representadas por linhas em vermelho) mostram, como esperado, que um fator de resposta de metano do DIC maior do que uma unidade aumenta relativamente a diferença entre as emissões ponderadas de etanol e de hidrocarbonetos não metano.

É interessante notar, pelos gráficos da Figura 15, que a emissão predominante de massa de etanol em gramas quando se analise cada uma das fases do ciclo de condução urbano completo se dá na fase 1 , em ensaios de veículos flex abastecidos com EHR (valor médio de 2,51 g, mediana de 1,77 g e média ponderada de 2,477 g).

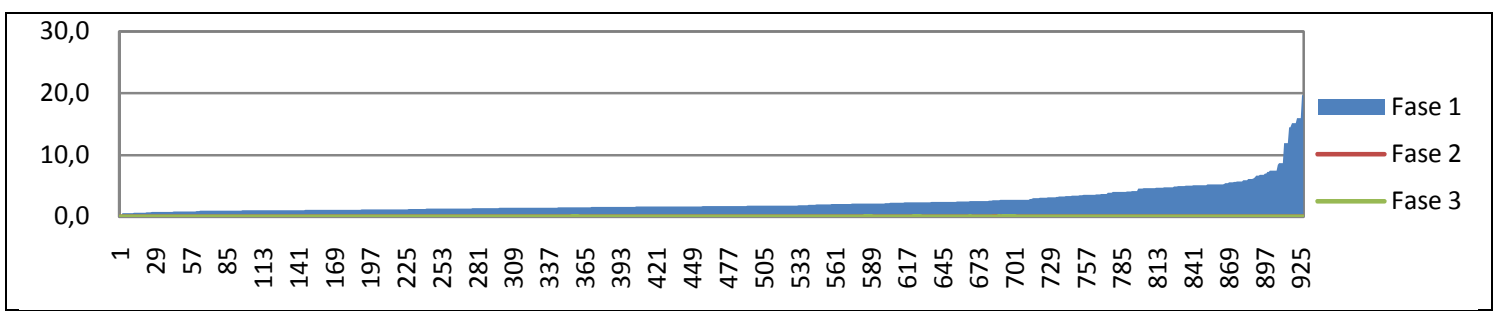

Figura 15. Gráficos das emissões de massa por fase do ciclo de condução urbano completo de etanol contido no gás de escapamento em ensaios realizados com EHR, dados em [g].

Os valores das curvas referentes às fases 2 e 3 são em sua grande maioria nulos, tendo seus valores de média, mediana e moda nulos.Apenas 24 ensaios possuem valores de massa de etanol maiores do que zero para a fase 2 e 29 ensaios para a fase 3 , porém todos estes são próximos de zero (o maior valor dentre esses ensaios é de $0,064 \mathrm{~g})$.

O exposto acima é muito interessante, pois podemos concluir e confirmar que a emissão de etanol em ensaios de veículos abastecidos com etanol ocorre no momento da partida a frio. 
O etanol é considerado um combustível verde devido a associação com o ciclo do carbono e redução na emissão de alguns poluentes, porém aumenta a emissão de outros, como observado.

\subsection{Potencial de formação de ozônio[16]}

Quando se analisa a contribuição de cada um dos principais poluentes dos NMOG em potencial de formação de ozônio, pode-se observar que a contribuição da parcela referente apenas ao etanol ultrapassa em 13,87 \% dos 865 ensaios com EHR o limite máximo de potencial de formação de ozônio baseado no limite máximo de emissão de NMHC de veículos leves de passageiros vigente, fase L5 do PROCONVE, e futuro, fase L6 (Equação 23 e Figura 16).

Limite Potencial $\mathrm{O}_{3}=$ Limite NMHC $\times$ MIR $_{\mathrm{G}_{\text {Gasolina de Ref.L6 }}}$ (Equação 24)

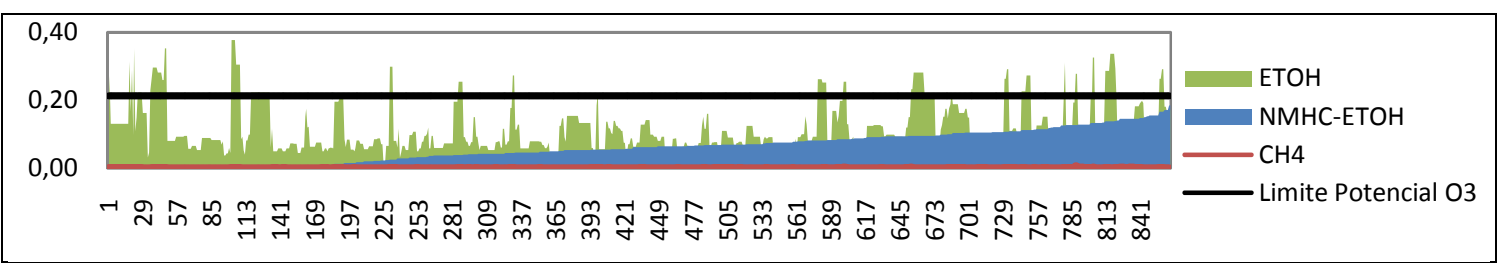

Figura 16. Gráfico do potencial de formação de ozônio baseado na contribuição individual das $\mathrm{ETOH}_{\mathrm{MP}}$, $(\mathrm{NMHC}-\mathrm{ETOH})_{\mathrm{MP}}$ e $\mathrm{CH}_{4 \mathrm{MP}}$ contidos no gás de escapamento em ensaios realizados com EHR, dados em [g de $\mathrm{O}_{3} / \mathrm{km}$ ].

Na Figura 16 também se observa que a curva referente ao potencial de formação de ozônio provindo da $\mathrm{CH}_{4 \mathrm{MP}}$ (curva em vermelho) contribuiu pouco com o potencial de formação de ozônio, como estimado teoricamente na seção 3. Apenas sete dos 288 ensaios que estariam reprovados pelo limite máximo de potencial de formação de ozônio adotado, 0,213 gramas de ozônio por quilômetro, passariam a atender este limite $(2,43 \%$ dos ensaios reprovados ou $0,81 \%$ dos ensaios totais analisados).

Analisando-se a contribuição total das emissões de $\mathrm{ETOH}_{\mathrm{MP}}$, (NMHC - ETOH) $)_{\mathrm{MP}}$, e, $\mathrm{CH}_{4 \mathrm{MP}}$ na obtenção do potencial de formação de ozônio referente aos NMOG, evidencia-se que 33,29\% dos ensaios estariam acima do limite máximo de potencial de formação de ozônio adotado, ou seja, as emissões de etanol contribuem para a formação de ozônio troposfériconestes casos (Figura 17).

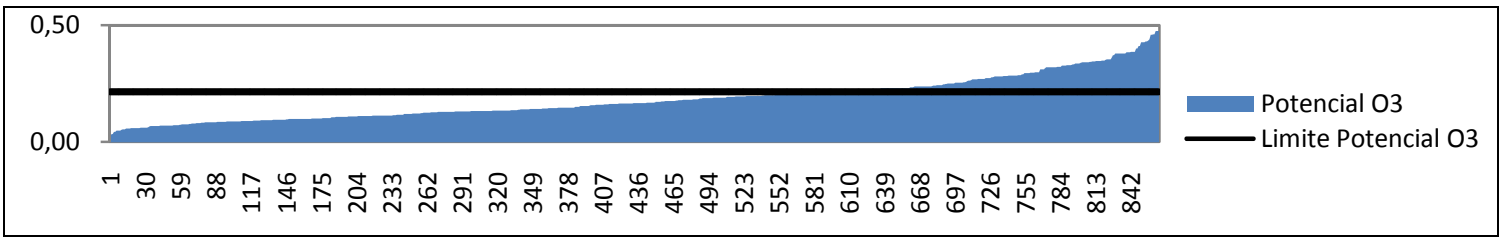

Figura 17. Gráfico do potencial de formação de ozônio baseado na contribuição total das $\mathrm{ETOH}_{\mathrm{MP}}$, $(\mathrm{NMHC}-\mathrm{ETOH})_{\mathrm{MP}}$ e $\mathrm{CH}_{4 \mathrm{MP}}$ contidos no gás de escapamento em ensaios realizados com EHR, dados em [g de $\mathrm{O}_{3} / \mathrm{km}$ ].

Nesta seção não se segregou dos hidrocarbonetos não metano descontado o etanol, $(\mathrm{NMHC}-\mathrm{ETOH})_{M P}$, os aldeídos totais, acetaldeído e formaldeído, portanto, estesnão foram contabilizados em separado no potencial de formação de ozônio, evitando-se contabilizar estes poluentes mais de uma vez. 


\section{CONCLUSÃO}

Este trabalho apresentou as principais definições relacionadas ao fator MIR e aos compostos NMOG, juntamente com a metodologia de cálculo associada a estes, evidenciando que a aplicação dos dois conceitos em nosso país é viável e trás benefícios ao meio ambiente e também à indústria automobilística.

A metodologia NMOG mostrou-se ser vantajosa, pois é um parâmetro já existente e aplicado nos EUA, tendo uma maior probabilidade de futura padronização mundial e existência de dados de referência, ligado ao fato do PROCONVE de veículos leves ser baseada na legislação americana.

Apenas um possível futuro limite máximo de emissões NMOG seria vinculado aos valores de MIR e não propriamente o parâmetro NMOG: Possíveis alterações nos valores de MIR, principalmente das mistura, como, por exemplo, NMHC e NONMHC, não refletem no mensurando, evitando-se correções em análises futuras.

O parâmetro NMOG descrito aqui pondera os aldeídos adequadamente, pois introduz o conceito NONMHC, como é realizado atualmente nos EUA, e pode ser aplicado diretamente à massa ponderada de seus componentes, sem grandes dificuldades.

Além do parâmetro NMOG limitar o potencial de formação de ozônio diretamente, indiretamente controla as emissões de etanol, pois já existe limites máximos de emissão para NMHC e CHO, sem criar uma imagem negativa ao combustível etanol, e, por associação, aos veículos flex (Figura 18).

$\overbrace{\overbrace{\mathrm{ETOH}} \mathrm{MP}}^{\text {Controle Indireto }}=\overbrace{\mathrm{NMOG}_{\mathrm{MP}}-\mathrm{NMHC}_{\mathrm{MP}}-\mathrm{CHO}_{\mathrm{MP}}}^{\text {Controle Direto }}$

Figura 18. Representação do controle indireto das emissões em termos de massas ponderadas de etanol.

Os valores deMIR NMHC $_{\text {e }}$ MIR $_{\text {NONMHC }}$ podem ser aperfeiçoados ao longo de futuras discussões, com a tendência a ser reduzido, pois o MIR teórico é superestimado, estando coerente com futuras fases do PROCONVE (fases mais rigorosas).

Resultados de emissão de aldeídos mostram que a emissão de acetaldeído é proporcionalmente maior do que a de formaldeído, tanto em ensaios realizados com gasool A22 referência como EHR. A grande maioria destes ensaios possui $\mathrm{CHO}_{\mathrm{MP}}$ abaixo de $50 \%$ do limite máximo do PROCONVE, o que possibilita discussões para atualização deste limite.

As emissões de acetaldeído são cerca de $85 \%$ maiores para ensaios realizado com EHR em relação aos realizados com gasool A22 referência, enquanto para o formaldeído os resultados são $66 \%$ maiores para EHR em relação ao gasool A22 referência.

A maior contribuição das emissões de aldeídos totais se processa durante a fase transitória fria, enquanto as emissões de etanol ocorrem predominantemente durante a partida a frio. 
As emissões ponderadas de metano são cerca de $60 \%$ maiores para veículos flex abastecidos com EHR em relação ao gasool A22 referência, o que pode ser significante pensando no potencial de mudanças climáticas deste poluente, apesar de não possuir limite no PROCONVE.

Cerca de $33 \%$ dos ensaios de veículos flex com EHR possuem emissões de etanol relevantes para a formação de ozônio troposférico, sendo considerado problemático.

\section{REFERÊNCIAS}

[1] Marcolin, Neldson. Era quase aguardente. Disponível em http://revistapesquisa.fapesp.br/2008/03/01/era-quase-aguardente/. Acesso em 03/03/2013.

[2] Utzeri, Fritz. Pra Quem Gosta de Automobilismo - Carro movido a cachaça Ernesto Lopes da Fonseca Costa. Disponível em http://www.int.gov.br/int90anos/ historiaINT02.pdf. Acesso em 03/03/2013.

[3] Revista Veja. Coleções - Proálcool. http://veja.abril.com.br/arquivo_veja/proalcoolalcool-etanol-geisel-petroleo-carros-flex-economia-exportacao-cana-de-acucar.shtml.

Acesso em 23/05/2013.

[4]Associação Nacional de Fabricantes de Veículos Automotores (ANFAVEA). Anuário da Indústria Automobilística Brasileira - 2012, São Paulo: FSC, 2012.

[5]Teich, Daniel Hessel. A consagração do carro flex. Disponível em http://exame.abril.com.br/revista-exame/edicoes/0870/noticias/a-consagracao-do-carroflex-m0082581. Acesso em 03/03/2013.

[6] Maffeis, João Neto. A história do carro flex no Brasil. São Paulo: Iqual - Inst. De Qualificação e Editora Ltda., 2009.

[7]Comissão Técnica de Acreditação de Laboratórios de Emissões. Ata da $88^{\text {a }}$ Reunião da Comissão Técnica de Acreditação de Laboratórios de Emissões - 07.12.2006.

[8]Norma ABNT NBR 6601:2012 - Veículos rodoviários automotores leves Determinação de hidrocarbonetos, monóxido de carbono, óxidos de nitrogênio, dióxido de carbono e material particulado no gás de escapamento.

[9]Comissão Técnicase Especiais -. Ata da 001 ${ }^{a}$ Reunião do Grupo de Trabalho de Álcool Não Queimado em 2012 - 07.03.2012.

[10 ] IBAMA. Programa de Controle da Poluição do Ar por Veículos Automotores.

Brasília: Ibama/Diqua, 2011.

[11] California Environmental Protection Agency - Air Resources Board. California Non-methane Organic Test Procedures. El Monte: CARB, 06/12/2012.

[12 Melo, Tadeu C. Cordeiro, et. al. Implantação dos Gases Orgânicos do Tipo Não Metano (NMOG) no Brasil. São Paulo: SIMEA, 2009.

[13] Resoluções ANP21/2009, 38/2009 e 57/2001.

[14]Norma ABNT NBR 12026:2009 - Veículos rodoviários automotores leves Determinação de aldeídos e cetonas contidos no gás de escapamento, por cromatografia líquida - Método DNPH.

[15] Norma ABNT NBR 15598:2008 - Veículos rodoviários automotores leves Determinação de etanol não queimado contido no gás de escapamento, por cromatografia gasosa - Método de ensaio.

[16] Dados levantados pela Companhia Ambiental do Estado de São Paulo, CETESB, dos relatórios de ensaios dos processos de homologação de veículos leves de passageiros flex referentes ao período de 2010 e 2011 e dados de análise crítica. 